\title{
Application of InSAR Modeling for Monitoring of Territories Under Landslides Risk in Armenia
}

\author{
Gurgen Aleksanyan
}

Geography and Geology Department, Yerevan State University, Yerevan, Armenia

Email address:

gurgenal@ysu.am

\section{To cite this article:}

Gurgen Aleksanyan. Application of InSAR Modeling for Monitoring of Territories Under Landslides Risk in Armenia. International Journal of Economy, Energy and Environment. Vol. 2, No. 1, 2017, pp. 1-6. doi: 10.11648/j.ijeee.20170201.11

Received: August 28, 2016; Accepted: October 28, 2016; Published: January 5, 2017

\begin{abstract}
In this article we describe works (that were carried out in the frames of NATO Project: NATO CLG: ESP.EAP.CLG. 983876) that have done for creating DEM for selected areas of Armenia with high level of risk where natural disasters such as grounds sedimentation, landslides, mudflows, earthquakes periodically happen. In the future the obtained DEM will be used to create regional system for the monitoring of natural disasters (to control topographic changes on the territories with high level of risk) in the territory of Armenia using tools such as InSAR modeling, systems of mathematical interpretation of digital models, GIS technologies and mathematical models for processing satellite images. The results of monitoring will be periodically presented to local authorities to take measures in order to prevent probable natural disasters impact on population and communications.
\end{abstract}

Keywords: Geological Data, Mudflows, Earthquakes, Topographical Maps, DEM, GIS, Processing of Satellite Images, Modeling

\section{Introduction}

During 2010-2011, joint scientific, Bulgarian - Armenian team (from the Free University of Burgas and the Yerevan State University) is implementing a project of NATO № 983876 (InSAR Modeling and monitoring of Geological Disaster Phenomena in Caucasus region - Armenia), the goal of which is the development of monitoring system for natural disasters (for example, areas where there are rocks of subsidence, landslides or earthquakes) on the territory of Armenia with the use of InSAR modeling tools, systems of mathematical interpretation of digital models, GIS technologies and mathematical models for handling complex images obtained from satellite ENVISAT (Tools SAR, established on satellites ERS - and ERS 2) and ASAR sensors. With the created monitoring system forecast of topographic changes in risk areas in Armenia, the evaluation of current situation on them and long-term forecast of probable natural disasters will be implemented.

Interferometric Synthetic Aperture Radar (InSAR) - a coherent active sensitive element of radiovision Interferometric SAR (In-SAR) technique is based on the phase difference information extracted from two complex valued SAR images acquired from different orbit positions and registered in sub-pixel level. This information is useful in measuring several geophysical quantities such as topography, slope, deformation (volcanoes, earthquakes, and ice fields), glacier studies, vegetation growth etc.

\section{Geologic Features of Armenia}

Armenia is situated in the seismically active crescent that stretches from the Alps through the Caucasus and Central Asia to the Russian Federation, along with Turkey and other earthquake-endangered countries. The substantial earthquake hazard is due to interactions of major tectonic plates: Indian and Arabian plates are moving north, colliding with the Eurasian plate and resulting in thrust faulting-the ongoing process that created the major mountain ranges from the Caucasus to the Himalayas.

\subsection{Landslides and Mudflows}

Landslide sites in the Republic of Armenia (Figure 1) cover about 122,000 hectares, which is $4.1 \%$ of country's total territory; some $35 \%$ of settlements are located on landslide-prone areas [1-4]. 233 communities (about 25\%) 
are affected by landslides, according to a recent study by the Japan International Cooperation Agency (JICA). Landslides are active in more than 100 communities and have affected hundreds of residential buildings, communication infrastructure, and vital facilities, including 1.744 hectares $5.2 \%$ of total residential space; 240 kilometers of roads/highways $-3.2 \%$ of the total; and 4.8 kilometers of railways $-0.5 \%$ of the total.

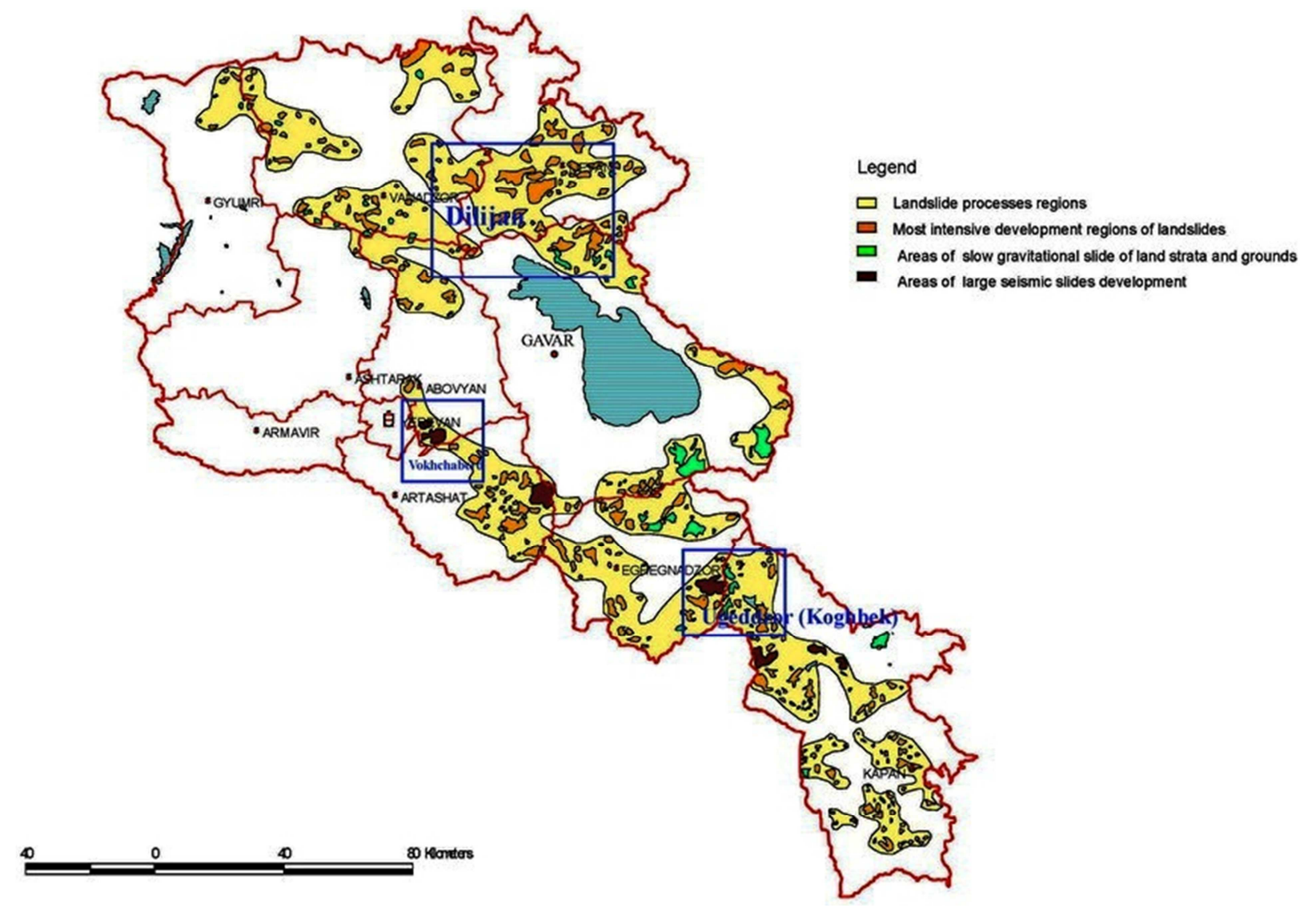

Figure 1. Landslides Armenia.

\subsubsection{Selection of Areas with High Level of Risk of Armenia}

The following works were carried out by the Armenian participants:

- Identification and selection of the areas of Armenia which are most exposed to seismic and landslide risk;

- Study of geological and morphological structures of selected areas;

- Study of topographic- geodesic information of risk areas before and after disaster as well as military topographical maps of the former USSR (mediumscales from 1:200 000 to 1:1000 000 and small-scales less then 1:1000 000);

- Study of large number of scientific-technical literature, technical reports and geological surveyance maps.

As a result of this research it was decided that tools ESA SAR first of all are necessary to be used to study the territories having landslides which are the most active and dimensioned and are dangerous for the population and infrastructure of the given area. ((Dilijan; Voghchaberd; Ughedzor (Kochbek) - Table 1) and Spitak 1988 earthquake zone.
Table 1. Coordinates of most active landslides of Armenia.

\begin{tabular}{lll}
\hline Name of landslip & $\begin{array}{l}\text { Latifude (Northern } \\
\text { breadth) }\end{array}$ & $\begin{array}{l}\text { Longitude (East } \\
\text { longitude) }\end{array}$ \\
\hline Voghchaberd & $40^{\circ} 10^{\prime} 00^{\prime \prime}$ & $44^{\circ} 39^{\prime} 10^{\prime \prime}$ \\
Dilijan & $40^{\circ} 45^{\prime} 10^{\prime \prime}$ & $44^{\circ} 53^{\prime} 15^{\prime \prime}$ \\
Ughedzor (Kochbeg). & $39^{\circ} 41^{\prime}$ & $45^{\circ} 43^{\prime}$ \\
\hline
\end{tabular}

\subsubsection{Voghchaberd Landslide}

This landslide is a block with $(2.5 \times 1.3) \mathrm{km}$ size and $(70$ $80) \mathrm{m}$ average power, broken from the steep slope of the mountain ridge of the same name and moved in the line of a fault of upthrust character which passes along the road near Voghchaberd village.

Here, the Palaeogene depositions are upthrust to Neogene. The southeast wing of the fault is raised.

The amplitude of vertical displacement of the block compiles approximately (200-225)m in case of significant (up to $1 \mathrm{~km}$ ) horizontal pulling out of landslide body. Such predominance of horizontal component over vertical one proves the seismogenic nature of the generation of this landslide.

The road (Figure 2) near Voghchaberd village is continually being deformed, intensive destruction of rural 
cemetery takes place, school building and more then 44 houses are completely destroyed, more than $80 \%$ of dwelling houses are in an emergency state.

The first damages caused by sliding movements at Voghchaberd village have been recorded as early as in 1982, but in the recent years after Spitak earthquake the landslide has become active again and retakes new sections of the village. The speed of sliding movements on separate areas is several millimeters a day. The movements are being strengthened after spring melting of snow and the rains since an intensive wetting of slip surface of landslide through fracture takes place during this period. Here, 1030 people (430 families) anxiously are waiting for their fate as a result of the existing alarm situation.

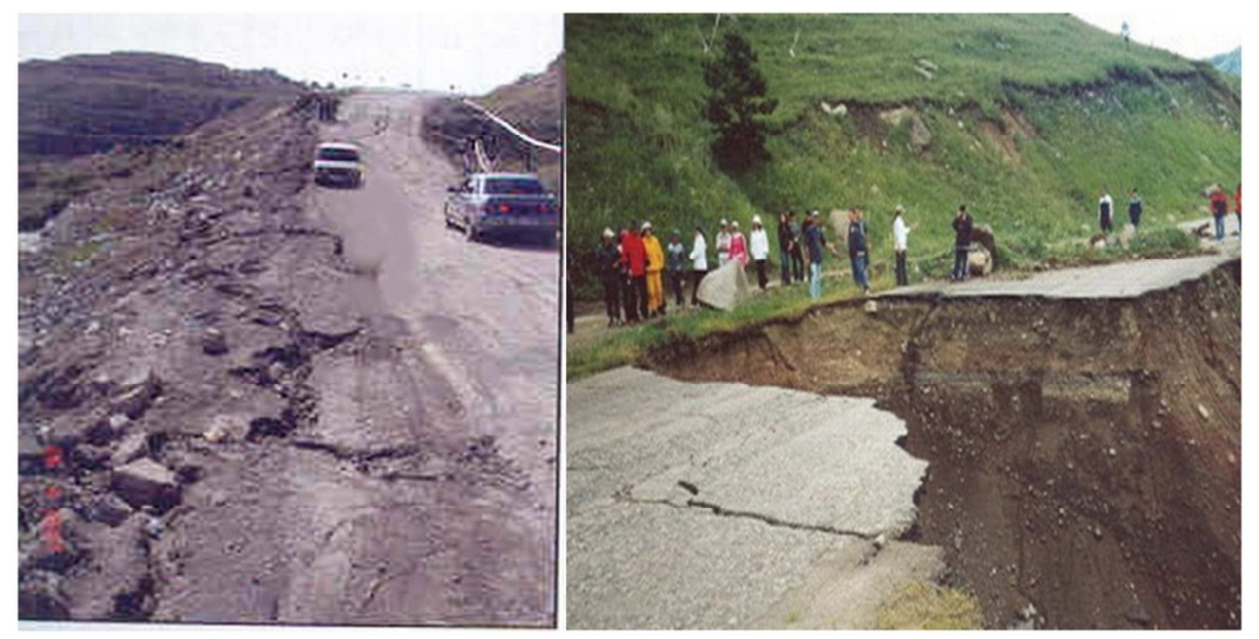

Figure 2. View of the road after landslide.

\subsubsection{Dilijan Landslides}

Landslides in the territory of Dilijan city are generally developed on the right slope of the Aghstev river valley. Here, more than 160 landslide manifestations of different intensity and sizes are distinguished [5].

The generation of Dilijan landslides is conditioned by a number of factors:

- Complicated geomorphological and geologic composition of the city territory;

- Marked lithologic composition of rocks, their intensive weathering, bentonitization, strong fracturing and fragmentation;

- Wide spread of subsoil waters and their outcropping;

- The differentiated movements of neotectonic blocks along the faults;

- The increasing of rock weight on slopes as a result of their moistening by atmospheric precipitations, excessive watering of farmlands and outflow of water from various sluices;

- Trimming and overloading of slopes during road laying and construction of heavy buildings etc..

The minimal sliding for 4 years has been registered on sliding area "Rotonda" $(0.6 \mathrm{~cm})$, and the maximum on "Jroger" area $(61.6 \mathrm{~cm})$.

The sliding of masses became more active after Spitak earthquake of 1988 and especially after USSR dissolution when the financing of anti-landslide measures has stopped. As a result, the territory of Dilijan city is in rather sad state: the sliding masses appear on the streets and on the various constructions on their way; asphalt in city centre reared from the pressure of sliding masses.

\subsubsection{Landslides of the Arpa River Left-Bank}

On the left-bank of the Arpa river the following landslide sections are known "Tnishik", "Martiros" (landslides of villages "Zaritap", "Martiros", "Sers" are also included here), "Artavan" (landslides in the Artavan river valley and near the village), "Akhta" (landslides in the Gyabutchay river valley and at villages Akhta, Kapuyt, Gomur) and "Ughedzor" (large landslide bodies at villages Ughedzor and Saravan).

Ughedzor (Kochbek) landslide occupies highway passing through Vorotan (Kochbek pass) and both sides of the Darb river valley between Saravan and Ughedzor villages. Here, in a volcanogenic -sedimentary strata in the line of the active fault (the epicenter of Vayoc-Dzor destructive earthquake $735 \mathrm{yr}(\mathrm{M}=6.5-7.0)$ is dated for it) some huge landslidesblocks have generated which are precisely fixed on the relief and on the topographic maps. These landslides continually deform road which is rather dangerous, since the given road is the only one connecting the capital of Armenia with the south of the republic and has strategic value. Landslide activity of the Ughedzor region, most likely, is connected with the activity of Vayoc-Dzor fault on which slow (creep) movements of its sides take place.

\subsection{Earthquakes}

Some 2541,200 people in 48 cities in Armenia are located in seismically active areas.11 historical earthquakes have reached magnitudes $(\mathrm{M})$ of 7.1 and the average recurrence interval of earthquakes with magnitudes of at least 5.5 is 30 to 40 years [6-8]. In 1839, after traveling around the Caucasus region, the French geographer F. Duba de Monpere wrote, "Armenia underwent and undergoes frequent and 
severe ground shaking". According to historical data, the following destructive earthquakes have taken place in Armenia:

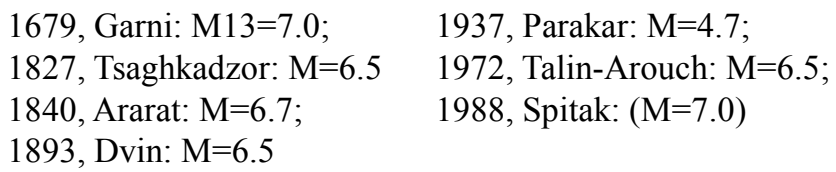

Yerevan (Capital of Armenia), home to 40 percent of Armenians, is in one of the highest seismic risk areas; a recent analysis of Yerevan building stock revealed that an earthquake with a magnitude of 7.0 or greater would destroy most buildings, potentially killing 300,000 people.

The Spitak earthquake in 7 December 1988 wasn't exclusive in the seismology by its main characteristics and other peculiar features. It was devastating tectonic earthquake of earth's crust. The earthquake hit $40 \%$ of the territory of Armenia, densely populated region with $1 \mathrm{ml}$ people. The affected area, where the intensity of the earthquake was greater then 8 , involved $30002 \mathrm{~km}$ area. 21 towns and 342 villages were destructed, 514.000 people were left without shelter, 20.000 people were injured and 12500 people were hospitalized. Number of victims was about 25.000 . Particularly in Gyumri (15.000-17.000) and in Spitak (4000) number of victims was more than anywhere else.

\section{Creation of Digital Elevation Models for Selected Risks Territories}

The topographic map of 1:100 000 scale of the territory of Armenia was taken as a basis to create digitized maps of the regions with high level of landslides and other ground displacements caused by earthquakes (Dilijan; Voghchaberd; Ughedzor (Kochbek) and the Spitak Earthquake Source Zone). In the map, the vertical shootings of areas were realized during 1950-1958, and the information of plan shooting was refreshed later in 1973-1980 years. All maps have been created with "Gauss Kruger" projection in "Polkovo 1942yr" coordinate system. The breaks between horizontals are $20 \mathrm{~m}$. Vertical shooting of the territory of Armenia was not done during last 25-30 years except some local territories.

The 1:100 000 scale topographic map of Armenia was used for general orientation, which was inputted into "ArcGIS Desktop 9.3 environment" by scanning its parts as digital-raster images (Figure 3).

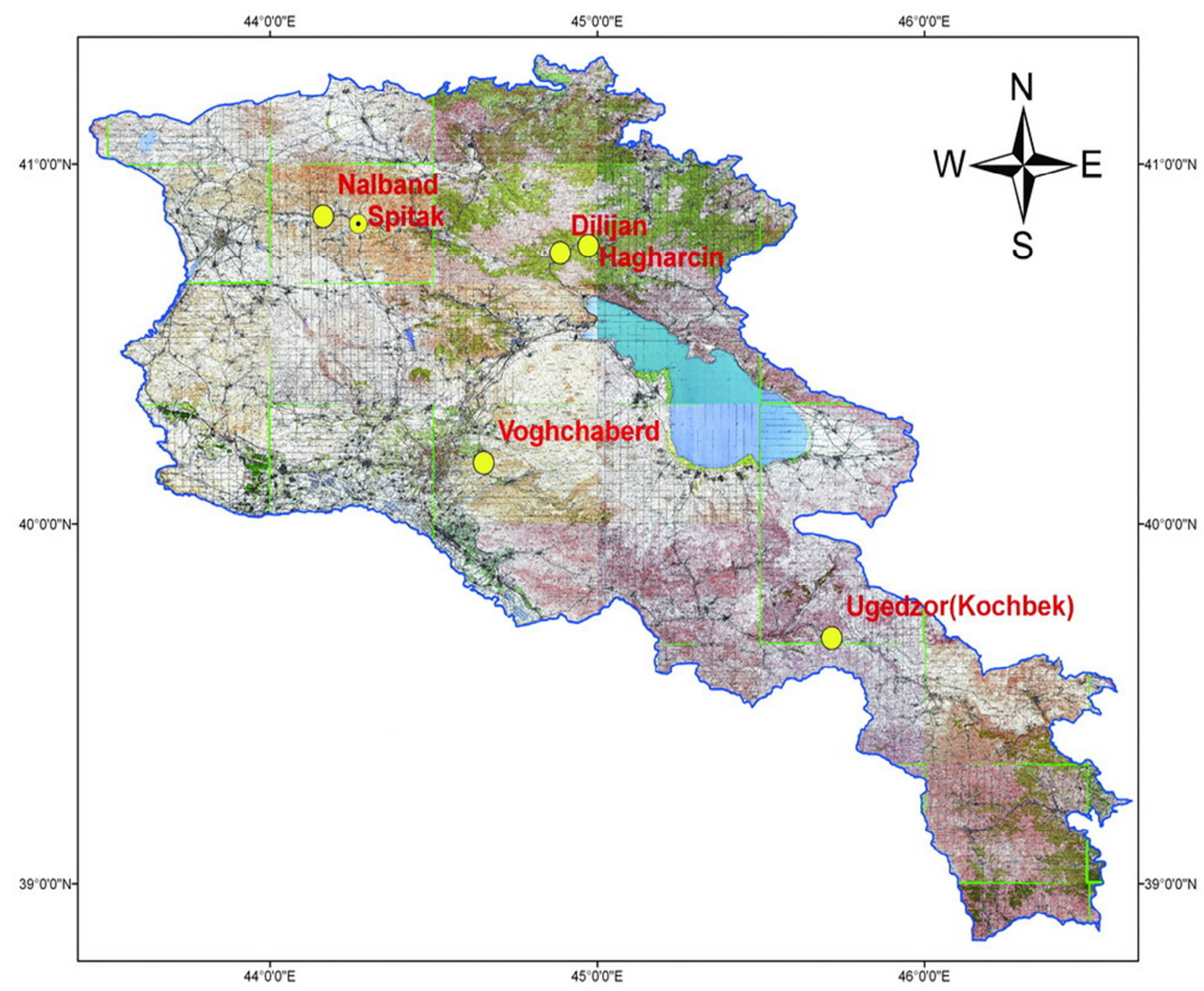

Figure 3. Raster of the 1:100 000 scale topographic map of Armenia 


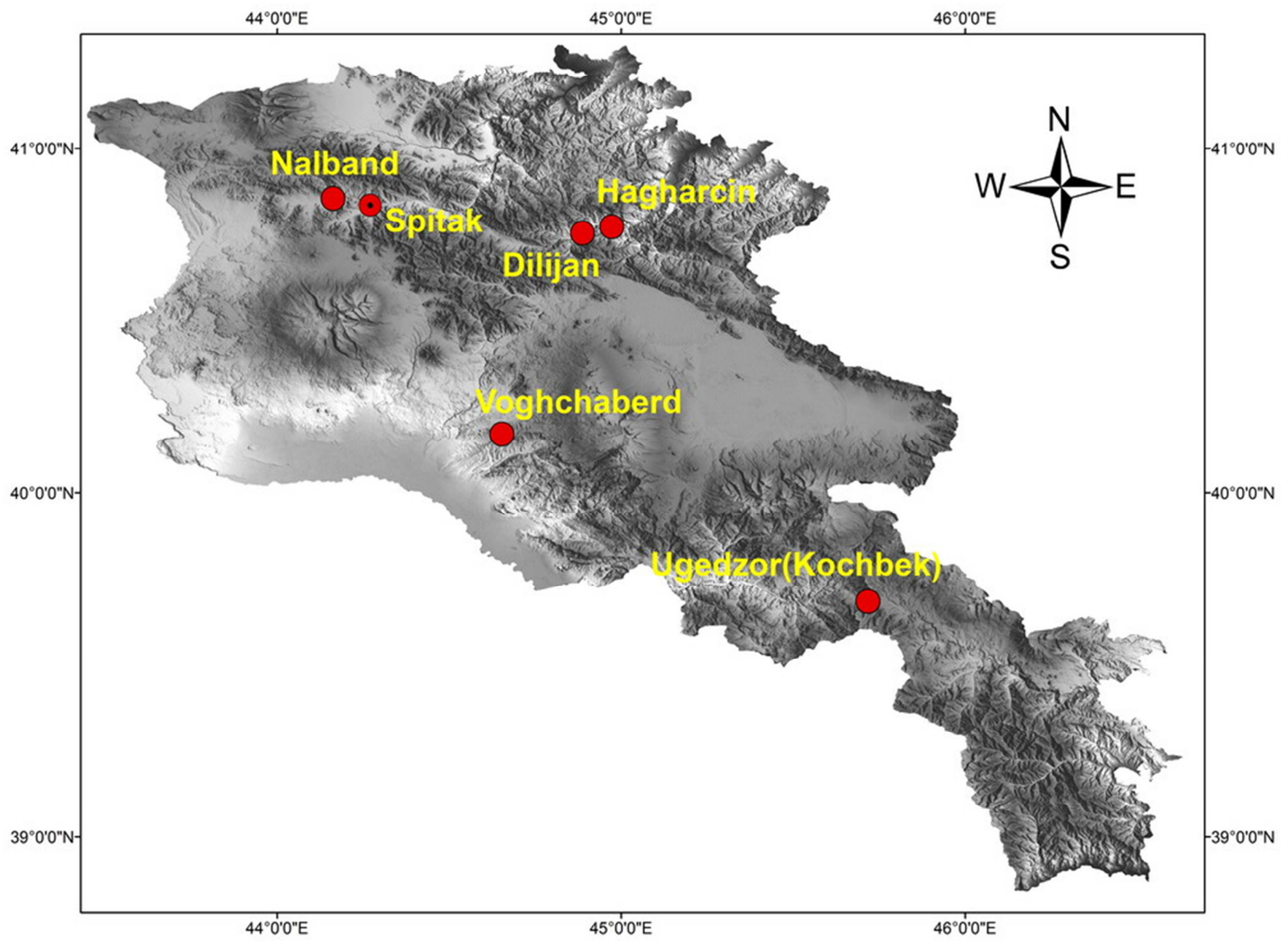

Figure. 4. The digital elevation model of Armenia.

The map was georeferenced with "Gauss Kruger" projection in "Polkovo 1942yr" coordinate system. Then for Dilijan, Voghchaberd, Ughedzor (Kochbeg) landslides and Spitak earthquake source zone areas $(100 \times 100 \mathrm{~km})$ were separated from the map which have been transformed and presented in the "WGS 1984".

For creation of DEM we have used DEM of Armenia (Figure 4) from the Advanced Spaceborne Thermal Emission and Reflection Radiometer (ASTER) instrument of the Terra satellite (available for $99 \%$ of the globe) which represents elevations at a 30 meter resolution [9-11].

DEM of Armenia is also presented in "WGS 1984" Geocentric Coordinate System.

Thereafter, for debugging of algorithms and programs for generation of differential interferograms for selected areas and signal processing models of SAR (for topographic interferometry), those are developed in frame of the project, from the DEM of Armenia authors have selected areas in accordance to the risk areas using the same principle that was applied in the processing of topographic maps of Armenia.
For simulations modeling of the Earth's surface movement caused by natural disasters (to debug algorithmic and software base for processing InSAR data of SAR) on the selected areas with high level of risk we have modeled the grounds movement.

In risk areas we have chosen landslides where depend on relief, local geological structure and composite rocks properties the grounds displacements are possible.

Selected landslides of $20 \times 20 \mathrm{~km}$ areas were cut from DEM of $100 \times 100 \mathrm{~km}$ area as in the future it will be impossible to create modified DEM for the whole territory.

All operations have been executed with use of ArcGis Desktop 9.3 and by widely using of ArcMap, ArcToolBox, Spatial Analyst Tools and 3D Analyst Tools. With the help of Spatial Analyst Tools/Surface/Contour tool from the DEM we have obtained the contours with $10 \mathrm{~m}$ intervals for the areas that must be moved. Next, on the base of displaced contours the modified DEMs have been obtained step by step and with the use of the following tools (Figure 5): 


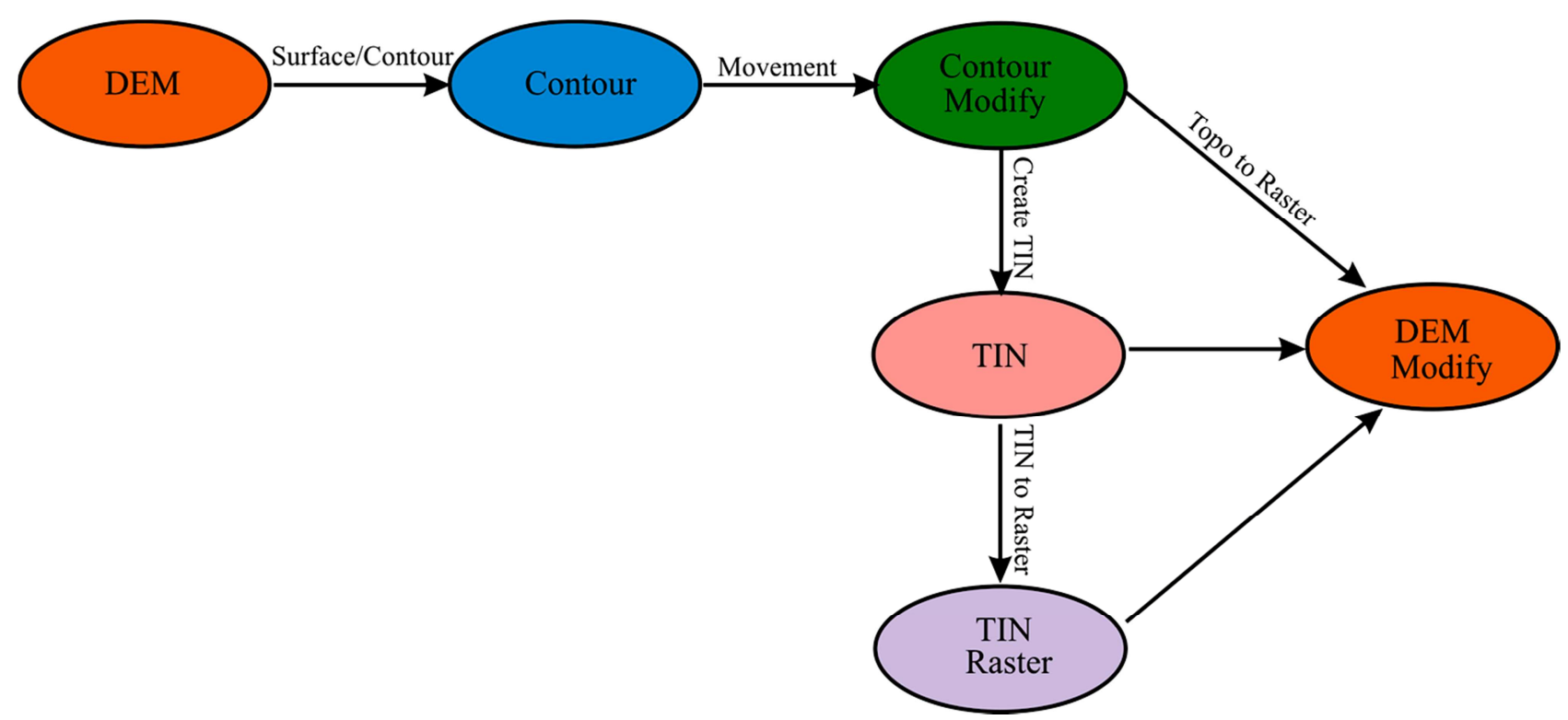

Figure 5. Graph of modified DEM generation.

For all risk areas the creation of the modified DEM in this way was fulfilled:

- The displaced parts in Dilijan and Haghartsin areas (corresponding coordinates of their centers are: $40^{\circ} 45^{\prime}$

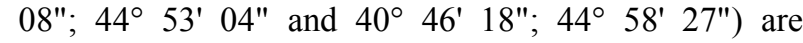
located in the left side of Aghstev river where the movements are directed to north.

- The displaced part in Ughedzor area (corresponding coordinates of its center are: $39^{\circ} 40^{\prime} 49^{\prime \prime}$; $\left.45^{\circ} 42^{\prime} 45^{\prime \prime}\right)$ is located in the right side of Vayk-Sisian highway where the movement is directed to north, north-east.

- The displaced part in Voghchaberd area (corresponding coordinates of its center are: $39^{\circ} 40^{\prime} 49^{\prime \prime}$; $45^{\circ} 42^{\prime} 45^{\prime \prime}$ ) is in $0.7 \mathrm{~km}$ distance to east, north-east from Voghchaberd village.

- The displaced part in Spitak earthquake source zone (corresponding coordinates of its center are: $40^{\circ} 52^{\prime}$ $\left.30^{\prime \prime} ; 44^{\circ} 10^{\prime} 58^{\prime \prime}\right)$ is in $3 \mathrm{~km}$ distance to east from Nalband village and $8 \mathrm{~km}$ to north-west from Spitak city. The displacement directed to south

Obtained two DEM will help to debug the developing mathematical models for processing satellite images which used in InSAR modeling system such topographical interferometry evaluation and differential interferometry evaluation of surface movement.

\section{References}

[1] Melkumyan M., Seismic Risk Assessment and Mitigation Strategy in Armenia

[2] Armenia Ministry of Nature Protection, National Action Program to Combat Desertification in Armenia (Government of Armenia, 2002
[3] Boynaghryan V. R., Stepanyan V. E., Khachatryan D. A. et al., Landslides in Armenia, "ASOGHIK", p. 308 (in Russian), 2009

[4] Zohrabyan L. N., Sahakyan G. D., Karakhanyan A. S., Landslide map of Armenian SSR at 1:200 000 scale based on decoding of aeroelevation images and geomorphologic investigations (explanation notes for the maps), Yerevan, Institute of Geological Sciences of Academy of Sciences SSRA, p. 36 (in Russian), 1981

[5] Vardanyan V. P., Proshyan A. S., Khachatryan D. A., Feature of the landslide structure of Fioletovo area in the Dilijan region of Armenian SSR, Scientific notes of YSU, Natural sciences, N: 1 (172), pp. 133-139.(in Russian), 1990

[6] Dorbath K., Arefiev S. and Rogozhin E., Seismic Tomography Constraints on the Deep Structure of the Spitak Earthquake Source Zone, Izvestiya, Physics of the Solid Earth, Vol. 40, No. 8, pp. 647-659. Translation from Fizika Zemli, No. 8, pp. 41-55, 2004

[7] Albarede F., Bogachkin B., Oleinik A., et al., On a Prehistoric Strong Earthquake in the Spitak Area, Dokl. Akad. Nauk Arm. SSR 313, (2), pp. 397-400, 1980

[8] Arefiev S., Aptekman Zh., Afimina T. et al., Catalog of Aftershocks of the Spitak, December 7, 1988 Earthquake, Fiz. Zemli, No. 11, pp. 60-73 (in Russian), 1991

[9] Wise S., Effect of differing DEM creation methods on the results from a hydrological model, Journal of Computers \& Geosciences, Volume 33, Issue 10, pp. 1351-1365, 2007

[10] Milana D., Heritageb G., Largec A. and I. Fuller, Filtering spatial error from DEMs: Implications for morphological change estimation, Journal of Geomorphology, Volume 125, Issue 1, pp. 160-171, 2011

[11] Sorensen R., J. Seibert, Effects of DEM resolution on the calculation of topographical indices: TWI and its components, Journal of Hydrology, Volume 347, Issues 1-2, 15, pp. 79-89, 2007 